\title{
A CLINICAL CASE STUDY OF NEUROPSYCHOLOGICAL COMPLICATIONS OF CHRONIC ALCOHOLISM IN COIMBATORE MEDICAL COLLEGE AND HOSPITAL
}

\author{
Banu Gopanar Balaraman1, Arulanandhan Ettiyan², Jayalakshmi Ramasamy³, Arjunan Senthil Kumaran ${ }^{4}$
}

${ }_{1}^{1}$ Assistant Professor, Department of Medicine, Chengalpattu Medical College and Hospital.

${ }^{2}$ Assistant Professor, Department of Medicine, Chengalpattu Medical College and Hospital.

${ }^{3}$ Assistant Professor, Department of Medicine, Chengalpattu Medical College and Hospital.

${ }^{4}$ Assistant Professor, Department of Medicine, Chengalpattu Medical College and Hospital.

\section{ABSTRACT}

\section{BACKGROUND}

'Alcoholism is a disease and alcohol is a disease agent' is the current concept about alcoholism. Alcoholism has its own good old historical background. Alcohol use disorder is one of the important global issues nowadays. Prevalence of alcohol use disorder is alarmingly increasing recently. As per statistical reports from standard journals, there is a competitive increase in number of female alcoholics in developing countries because of urbanisation and western acculturation.

This clinical study on neuropsychiatric complications of chronic alcoholism is purely based on history and clinical manifestations. To select chronic alcoholics as subjects in a government medical college was very easy, but excluding the one s with other complications made this a little bit challenging and interesting experience.

The ultimate aim of this study is not only to observe the complications but also to create awareness regarding alcohol use disorders. Also it is an eye opener for the people who open the bottle impulsively, at least to some extent.

\section{MATERIALS AND METHODS}

This study was done at Coimbatore Medical College Hospital, Coimbatore, from March 2010 to November 2011. Study Design is a cross-sectional study. A thorough general and systemic clinical examination and appropriate investigations were done after applying inclusion and exclusion criteria.

\section{RESULTS}

Middle aged (30-40 years) alcohol users are more prone to neuropsychiatric complications of alcoholism. Prevalence of female alcohol users is increasing and they are more affected by psychiatric complications. Both neurological and psychiatric complications occur in the same patient more commonly. The most common neurological complication is peripheral neuropathy. The most common psychiatric complication is mood disorder.

\section{CONCLUSION}

Even shorter duration of alcoholism causes neuropsychiatric complications. Consumption of spirits (distilled beverages) is more common in our country. AUDIT is more efficient than CAGE scoring in identifying problem drinkers. Willingness for de-addiction is more among chronic alcohol users.

\section{KEYWORDS}

Alcohol Addiction, Alcohol Dependence, Peripheral Neuropathy, Cerebellar Degeneration, Mood Disorders.

HOW TO CITE THIS ARTICLE: Balaraman BG, Ettiyan A, Ramasamy J, et al. A clinical case study of neuropsychological complications of chronic alcoholism in Coimbatore Medical College and Hospital. J. Evolution Med. Dent. Sci. 2017;6(10):799-803, DOI: $10.14260 /$ Jemds/2017/173

\section{BACKGROUND}

'Alcoholism is a disease and alcohol is a disease agent' is the current concept about alcoholism. Alcoholism has its own good old historical ${ }^{1}$ background.

Alcohol use disorder is one of the important global issues $^{2,3}$ nowadays. There are so many terminologies to describe alcohol use according to the pattern of drinking like occasional users and hazardous users.

Recently, the term 'alcohol addiction' is not used because of its derogatory nature, instead alcohol dependence is used.

Financial or Other, Competing Interest: None.

Submission 25-12-2016, Peer Review 17-01-2017,

Acceptance 24-01-2017, Published 02-02-2017.

Corresponding Author:

Banu Gopanar Balaraman,

Assistant Professor,

Department of Medicine,

Chengalpattu Medical College,

Chengalpattu.

E-mail: banugopan5574@gmail.com

DOI: $10.14260 /$ jemds $/ 2017 / 173$

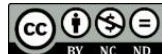

Consumers of moderate amounts of alcohol with proper self-control are proven to be medically beneficial. Hence, they are called 'social drinkers'.

Prevalence of Alcohol Use Disorders is alarmingly increasing recently. As per statistical reports from standard journals, there is a competitive increase in number of female alcoholics in developing countries ${ }^{4,5}$ because of urbanisation and western acculturation.

This clinical study on neuropsychiatric complications of chronic alcoholism is purely based on history and clinical manifestations. To select chronic alcoholics as subjects in a government medical college was very easy, but excluding the ones with other complications made this a little bit challenging and interesting experience.

"The very first human personality which dissolves in the alcohol is dignity". Most of the drinkers start this magical liquid for the solution of their life time problems, but unfortunately end with multispectrum of problems. Alcohol dependent individuals are so addicted they feel like drinking all the time.

The ultimate aim of this study is not only to observe the complications $^{6}$ but also to create awareness regarding 
alcohol use disorders. Also, it is an eye opener for the people who open the bottle impulsively, at least to some extent.

\section{MATERIALS AND METHODS}

This study was done at Coimbatore Medical College Hospital, Coimbatore from March 2010 to November 2011 after getting approval from the ethical committee.

Study Design is a cross-sectional study.

Inclusion criteria-100 patients from Medical, Neurological and Psychiatry Department, age 20-50 years, both male and female and at least 5 years of alcohol abuse. Exclusion criteria - Age Less than 20 and more than 50 years, other systemic illnesses due to alcoholism, other substance abuse, other aetiologies for neuropsychiatric illnesses like HIV, DM, HT, CVA, TB, etc.

A detailed history was taken from all enrolled patients with informed consent which included neurological complaints, psychiatric complaints, history of previous illness including DM/HT/TB/liver disorders/HIV/STD, etc. History of old CVA and seizures, personal history including diet, smoking, drug abuse, marital status, extramarital relations were taken.

A thorough general and systemic clinical examination was done with the assessment of following factors: General examination, vital signs, systemic examination with assessment of higher mental functions, cranial nerves, spinomotor system, autonomic nervous system, peripheral nerves and cerebellar functions were done. Laboratory tests include routine blood tests (CBC, Hb, Sugar), Urine routine (Albumin, Sugar, Deposits), liver function tests, renal function tests, CT scan brain, STD panel were done to rule out other illnesses. Alcohol related evaluation was done using the following scoring systems: MMSE, CAGE questionnaire and AUDIT administered in interview version. All patients were advised to undergo counselling for de-addiction after explaining health hazards of alcoholism. All the data were tabulated and statistically analysed. Statistical analysis was done with relevant data.

\section{RESULTS}

\section{Age Distribution}

In this study of 100 cases of chronic alcoholism, the age distribution is as follows: Less than 30 years is $16 \%, 30-40$ years is $62 \%$ and above 40 years is $22 \%$.

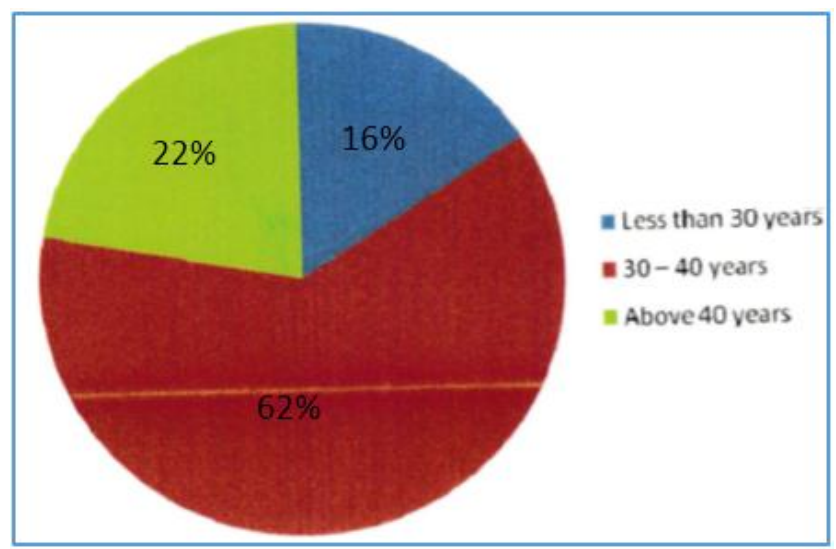

Figure 1. Predominant Age Group is $30-40$ which accounts for $62 \%$
Gender Distribution

In this study of 100 cases of chronic alcoholism, the gender distribution is observed as given below.

\begin{tabular}{|c|c|c|}
\hline Gender Distribution & Frequency & Percentage \% \\
\hline Male & 88 & 88 \\
\hline Female & 12 & 12 \\
\hline Table 1. Males were Predominantly affected by Chronic \\
Alcoholism accounting to 88\% \\
\hline
\end{tabular}

\section{Marital Status Distribution}

In this study of 100 cases of chronic alcoholism, the marital status distribution observed is $78 \%$ married and $22 \%$ single.

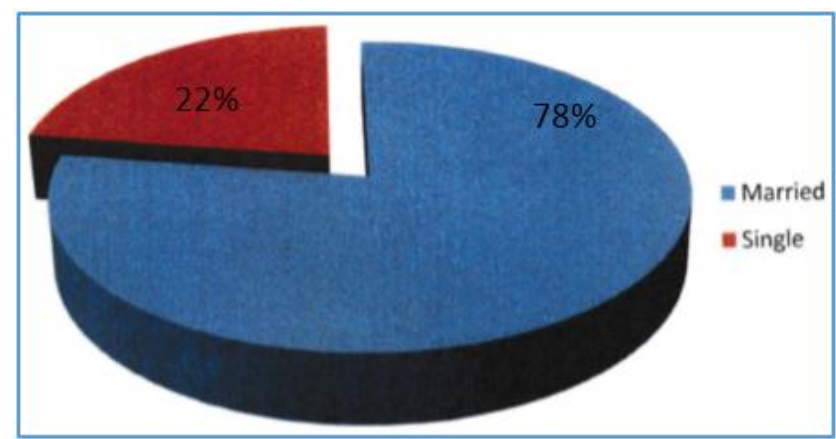

Figure 2. Married Persons were more involved accounting to $78 \%$

\section{Type of Alcohol Distribution}

In this study of 100 cases of chronic alcoholism, the type of alcohol distribution is observed as given below.

\begin{tabular}{|c|c|c|}
\hline Alcohol & Frequency & Percentage\% \\
\hline Spirit & 69 & 69 \\
\hline Beer & 26 & 26 \\
\hline Wine & 3 & 3 \\
\hline Others & 2 & 2 \\
\hline \multicolumn{2}{|c|}{ Table 2. Predominant Type of Alcohol consumed is Spirits } \\
accounting to 69\% \\
\hline
\end{tabular}

\section{Duration of Consumption Distribution}

In this study, the duration of consumption distribution is as follows: Less than 10 years is $38 \%, 10-15$ years is $31 \%, 15-20$ years is $23 \%, 20-25$ years is $6 \%$ and above 25 years is $2 \%$.

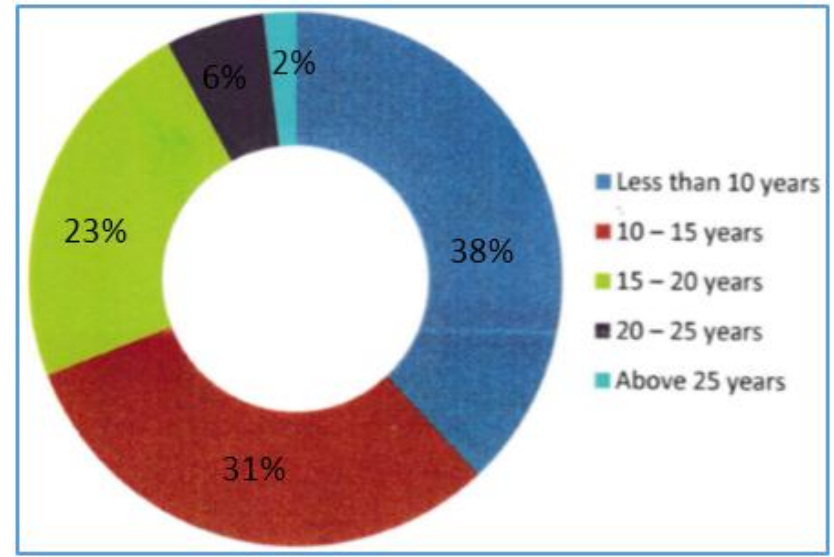

Figure 3. More Prevalent Duration is Less than 10 years accounting to $38 \%$ 


\section{Frequency of Consumption Distribution}

In this study of 100 cases of chronic alcoholism, the frequency of consumption distribution is observed as given below.

\begin{tabular}{|c|c|c|}
\hline Frequency of Consumption & Frequency & Percentage \% \\
\hline Monthly once or less & 3 & 3 \\
\hline 2-4 times per month & 9 & 9 \\
\hline 2-3 times per week & 22 & 22 \\
\hline More than 4 times per week & 66 & 66 \\
\hline
\end{tabular}

Table 3. Those who consume Alcohol for more than 4 times per week are More Prevalent accounting to $66 \%$

\section{Distribution of Complications}

In this study of 100 cases of chronic alcoholism, the distribution of complications is observed as given below.

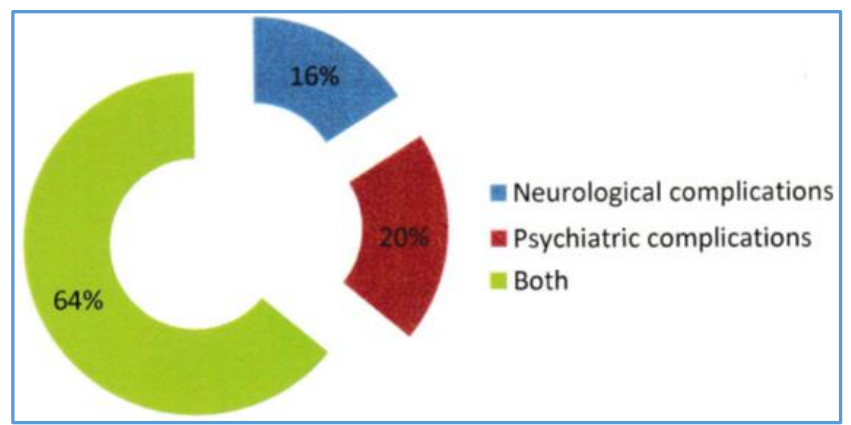

Figure 4. Neuropsychiatric Complications are more Common than Isolated Complications accounting to 64\%

Neurological Complications Distribution

In this study of 100 cases of chronic alcoholism, the neurological complications distribution is observed as given below.

\begin{tabular}{|c|c|c|}
\hline Complication & Frequency & Percentage \% \\
\hline Encephalopathy & 12 & 12 \\
\hline Stroke & 2 & 2 \\
\hline Peripheral Neuropathy & 52 & 52 \\
\hline Myopathy & 6 & 6 \\
\hline Cerebellar Degeneration & 8 & 8 \\
\hline Nil & 20 & 20 \\
\hline \multicolumn{3}{|c|}{$\begin{array}{c}\text { Table 4. Peripheral Neuropathy is More Prevalent than } \\
\text { other Complications accounting for } 52 \%\end{array}$} \\
\hline
\end{tabular}

Psychiatric Complications Distribution

In this study of 100 cases of chronic alcoholism, the psychiatric complications distribution is observed as given below.

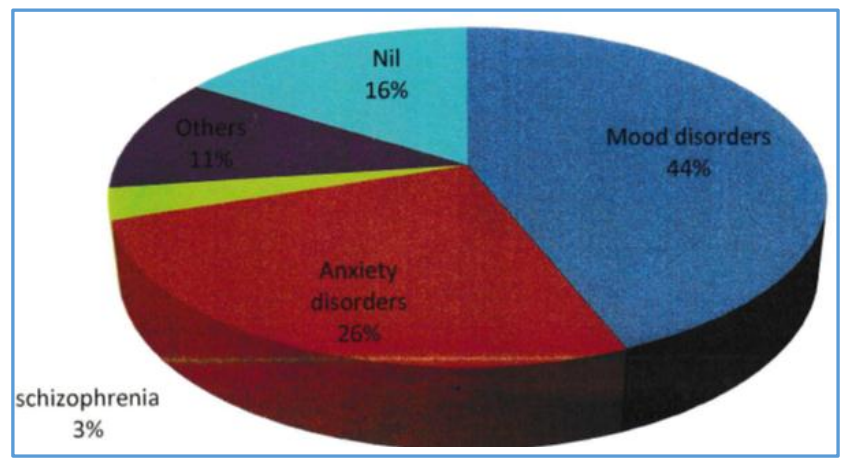

Figure 5. Mood Disorders are More Prevalent than other Complications accounting for $44 \%$

\section{CAGE Score Interpretation}

In this study of 100 cases of chronic alcoholism, the interpretation of CAGE scoring is observed as given below.

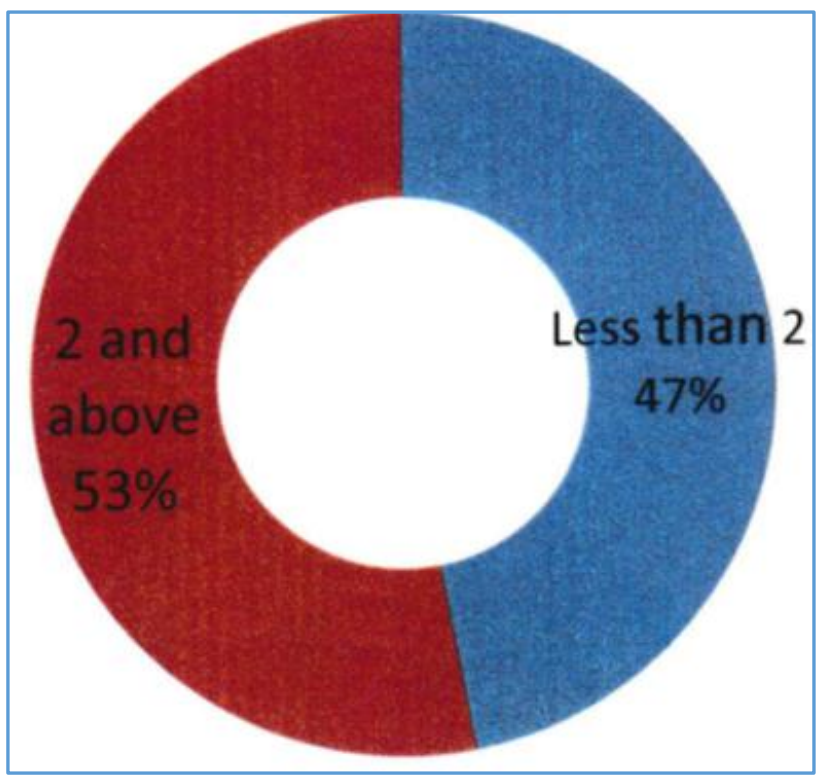

Figure 6. CAGE identifies 53\% as Problem Drinkers

\section{AUDIT Zone Distribution}

In this study of 100 cases of chronic alcoholism, the AUDIT Zone distribution is observed as given below.

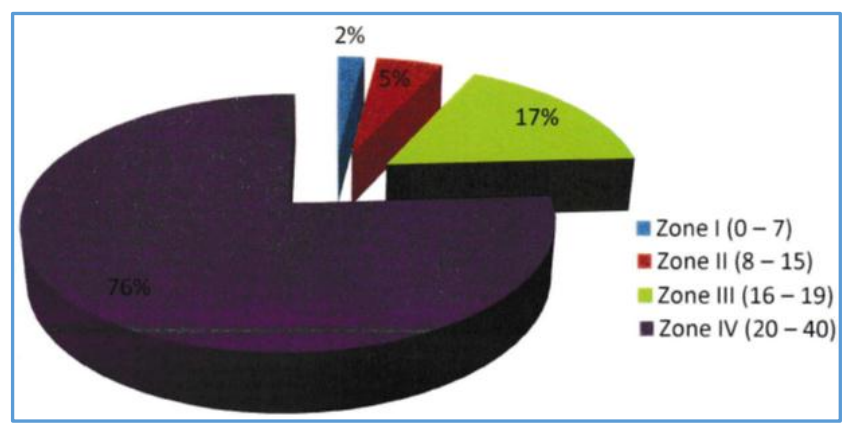

Figure 7. AUDIT identifies 76\% as Problem Drinkers

\section{De-Addiction Willingness Distribution}

In this study of 100 cases of chronic alcoholism, the deaddiction willingness distribution is observed as given below.

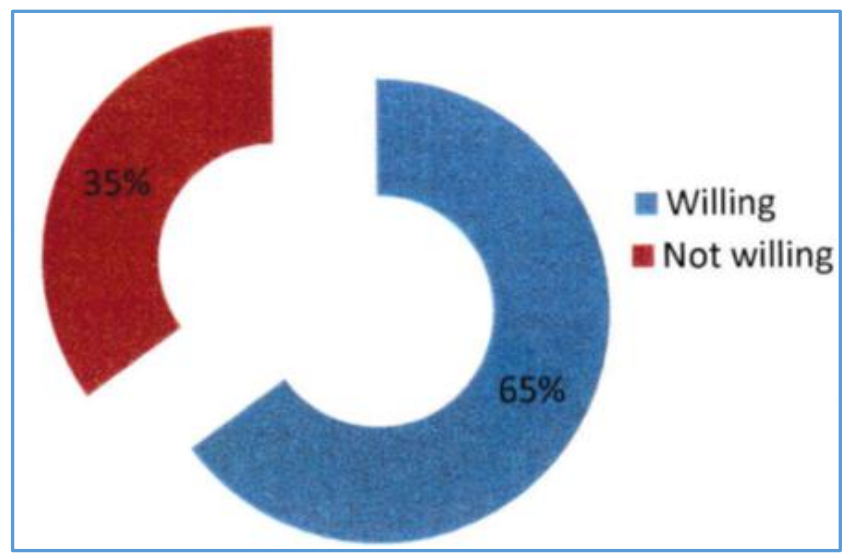

Figure 8. 65\% were willing for De-addiction 


\section{DISCUSSION}

This study about chronic alcoholism is notable for significant results.

According to age as criteria, middle aged subjects (30-40 years) account for $62 \%$, young age group (less than 30 years) for $16 \%$ and older age group (more than 40 years) for $22 \%$ of alcoholics with neuropsychiatric complications. This shows that middle aged group is more prone to developing neuropsychiatric complications. This data correlates well with global status report on alcoholism by WHO.7,8

Gender prevalence as observed by this study shows $88 \%$ were male and $12 \%$ were female. This shows increasing number of female alcoholics than in the past years. This data correlates well with the study by Cadoret et $\mathrm{al}^{5}$ published in International Journal of Epidemiology.

Marital status as a parameter which showed that more married people (78\%) are alcoholics than unmarried people (22\%). Thus, marital status is also an influencing factor for alcoholism.

According to the type of alcohol consumed, spirits (distilled beverages) accounted for $69 \%$, beer $26 \%$, wines $3 \%$ and others for $2 \%$ of consumption. This shows that spirits are the most consumed type of alcohol in our country. This data correlates with the global status report on alcohol by WHO.7,8 As with the duration of consumption, the most prevalent group is less than 10 years accounting for 38\% followed by 10 - 15 years (31\%), $15-20$ years $(23 \%), 20-25$ years $(6 \%)$ and above 25 years (2\%). This shows that neuropsychiatric complications occur earlier than other complications. When the duration of consumption increases other complications of alcoholism intervene, this is an exclusion criterion for this study.

As with frequency of drinking those who consume alcohol for more than 4 times a week are more affected (66\%) followed by 2-3 times per week (22\%), 2-4 times per month (9\%) and monthly once or less (3\%) by neuropsychiatric complications. This shows that occasional alcoholics have a lesser risk of complication than regular drinkers.

Distribution of complications among alcoholics: Those with only neurological complications- $16 \%$, those with only psychiatric complications- $20 \%$, and those with both complications are $64 \%$. This infers that alcoholism can cause both neurological and psychiatric complications in the same patient, than presenting as an isolated problem. This shows multispectrum of disease pattern of alcoholism.

The most common neurological complication observed is peripheral neuropathy (52\%) followed by encephalopathy (12\%), cerebellar degeneration (9\%), myopathy (6\%) and stroke (2\%). This data correlates well with the data of study by Koike et $\mathrm{al}^{9}$ on peripheral neuropathy in chronic alcoholism, published in the Journal of Current Opinions in Neurology.

The most common psychiatric complication observed is mood disorders (44\%), followed by anxiety disorders (26\%), schizophrenia (3\%) and others (11\%). This showed that mood disorders like depression, mania and bipolar disorders are more common in chronic alcoholics. This data correlates well with the study of Blankfield A et al published in Journal of Substance Abuse Treatments. ${ }^{10}$

As per the interpretation of CAGE scoring identified, 53\% of the subjects were problem drinkers and $47 \%$ with scores less than 2.
Interpretation of AUDIT scoring identified $76 \%$ in zone IV that is harmful drinkers, $17 \%$ in zone III, $5 \%$ in zone II, and only $2 \%$ as in zone I.

Thus, AUDIT is more superior in identifying problematic harmful drinkers than CAGE scoring. This data correlates well with data of study of McCusker M.T et al published in Oxford International Journal of Medicine, QJM.

On assessing the willingness of the subjects for deaddiction, $65 \%$ were willing for de-addiction and treatment for alcohol related disorders. $35 \%$ were not willing for deaddiction.

\section{CONCLUSION}

- Middle aged (30-40 years) alcohol users are more prone to neuropsychiatric complications of alcoholism.

- Prevalence of female alcohol users is increasing and they are more affected by psychiatric complications.

- Both neurological and psychiatric complications occur in the same patient more commonly.

- The most common neurological complication is peripheral neuropathy.

- The most common psychiatric complication is mood disorder.

- Even shorter duration of alcoholism causes neuropsychiatric complications.

- Consumption of spirits (distilled beverages) is more common in our country.

- AUDIT is more efficient than CAGE scoring in identifying problem drinkers.

- Willingness for de-addiction is more among chronic alcohol users.

\section{REFERENCES}

[1] Finnish Foundation for Alcohol Studies. International statistics on alcoholic beverages: Production, trade and consumption 1950-1972. In: the Finnish foundation of alcoholic studies and the world health organization regional office for Europe, Forssa, Finland, Aurasen Kirjapaino. Distributed by Finnish foundation for alcohol studies Helsinki, Finland 1977.

[2] Lopez AZ, Ezzati M, Rodgers A, et al. Comparative quantification of health risks. Global and regional burden of disease attributable to selected major risk factors. Geneva: World Health Organization 2004;1:9591108.

[3] Rehm J, Klotsche J, Patra J. Comparative quantification of alcohol exposure as risk factor for global burden of disease. Int J Methods Psychiatr Res 2007;16(2):66-76.

[4] Ammendola A, Gemini D, Lannaccone S, et al. Gender and peripheral neuropathy in chronic alcoholism: a clinical electroneurographic study. Alcohol Alcohol 2000;35(4):368-71.

[5] Cadoret RJ, Yates WR, Troughton E, et al. An adoption study of drug abuse/dependency in females. Compr Psychiatry 1996;37(2):88-94.

[6] Murray RM, Edwards G, Gross MM. Screening and early detection instruments for disabilities related to alcohol consumption. In: Edwards G, Gross MM, Keller M, et al. Alcohol-related disabilities. WHO offset pub. No 32. Geneva: World Health Organization 1977;32:89-105. 
[7] World Health Organization. Global status report on alcohol. Geneva: Department of mental health and substance abuse 1999.

[8] World Health Organization. Global information system on alcohol and health (GISAH) Geneva 2010. http://www.who.inUglobalatlas/alcohol.
[9] Koike H, Mori K, Misu K, et al. Painful alcoholic polyneuropathy with predominant small-fiber loss and normal thiamine status. Neurology 2001;56(12):172732.

[10] Field BA. Psychiatric symptoms in alcohol dependence: diagnostic and treatment implications. Journal of Substance Abuse Treatment 1986;3(4):275-78. 